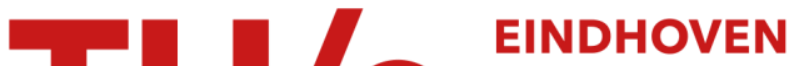 UNIVERSITY OF TECHNOLOGY
}

\section{Limitations in the design of ancillary service markets imposed by communication network delays}

\section{Citation for published version (APA):}

Hermans, R. M., Jokic, A., Bosch, van den, P. P. J., Frunt, J., Kamphuis, I. G., \& Warmer, C. J. (2010). Limitations in the design of ancillary service markets imposed by communication network delays. In Proceedings of the 7th IEEE International Conference on the European Energy Market (EEM 2010), 23-25 June 2010, Madrid, Spain (pp. 1-6). Institute of Electrical and Electronics Engineers.

https://doi.org/10.1109/EEM.2010.5558671

DOI:

10.1109/EEM.2010.5558671

Document status and date:

Published: 01/01/2010

\section{Document Version:}

Publisher's PDF, also known as Version of Record (includes final page, issue and volume numbers)

\section{Please check the document version of this publication:}

- A submitted manuscript is the version of the article upon submission and before peer-review. There can be important differences between the submitted version and the official published version of record. People interested in the research are advised to contact the author for the final version of the publication, or visit the $\mathrm{DOI}$ to the publisher's website.

- The final author version and the galley proof are versions of the publication after peer review.

- The final published version features the final layout of the paper including the volume, issue and page numbers.

Link to publication

\section{General rights}

Copyright and moral rights for the publications made accessible in the public portal are retained by the authors and/or other copyright owners and it is a condition of accessing publications that users recognise and abide by the legal requirements associated with these rights.

- Users may download and print one copy of any publication from the public portal for the purpose of private study or research.

- You may not further distribute the material or use it for any profit-making activity or commercial gain

- You may freely distribute the URL identifying the publication in the public portal.

If the publication is distributed under the terms of Article 25fa of the Dutch Copyright Act, indicated by the "Taverne" license above, please follow below link for the End User Agreement:

www.tue.nl/taverne

Take down policy

If you believe that this document breaches copyright please contact us at:

openaccess@tue.nl

providing details and we will investigate your claim. 


\title{
Limitations in the design of ancillary service markets imposed by communication network delays
}

\author{
R. M. Hermans Student Member, IEEE, A. Jokić, Member, IEEE, P. P. J. van den Bosch, Member, IEEE, \\ J. Frunt, Student Member, IEEE, I. G. Kamphuis, and C. J. Warmer
}

\begin{abstract}
Real-time balancing of the European electricity grid will become increasingly dependent on market-based control mechanisms that are enabled by connecting millions of prosumers to an open communication network. The use of communication systems inevitably introduces delays in the energy balancing control loop, which could endanger market operation and stability of the electricity grid. By investigating the interaction between pricebased control algorithms for real-time balancing and information and communication technology, we aim to provide systematic design rules for unrestricted ancillary service markets.
\end{abstract}

Index Terms-ancillary services, real-time balancing, pricebased control, two-sided markets, decentralized solutions, smartgrid technologies

\section{INTRODUCTION}

A $\mathrm{N}$ important prerequisite for reliable and stable operation of the electrical power grid is that generation and load are balanced at all time, as efficient ways of storing electrical energy do not yet exist. Conventionally, real-time balancing (or load-frequency control) is implemented by directly adjusting centralized, large-scale supply to fluctuations in demand. Today however, the share of electricity generated by large power plants is decreasing significantly, as the electrical power network is subject to a growing penetration of distributed generation (DG). As a result, centralized control of the electricity grid is becoming increasingly difficult, which motivates the need for new, distributed balancing arrangements.

In the deregulated European electrical energy network, realtime balancing and noncentralized decision making is likely to be implemented via open markets for ancillary services (AS), see for instance [1], [2]. Effective operation of these markets, and hence a stable operation of the grid, requires every market player to be connected to an open communication infrastructure over which price signals and bids can be transmitted. However, the use of communication systems inherently introduces constant or time-varying delays in the control loop, which could endanger market operation and stability of the electricity grid. Although the effects of time delays on load-frequency control have been studied before (see e.g., [3]-[6] and the references therein), most of these

R. M. Hermans, A. Jokić, P. P. J. van den Bosch and J. Frunt are with the Department of Electrical Engineering, Eindhoven University of Technology, P.O. Box 513, 5600 MB Eindhoven, The Netherlands, E-mails: \{r.m.hermans, a.jokic, p.p.j.v.d.bosch, j.frunt\}@tue.nl.

I. G. Kamphuis and C. J. Warmer are with the Efficiency \& Infrastructure Unit, Intelligent Energy Grids Research Program, Energy research Centre of the Netherlands, P.O. Box 1, 1755 ZG Petten, The Netherlands, E-mails: \{kamphuis, warmer\}@ecn.nl. articles focus on direct, i.e., power-based, control of largescale supply. To the best of our knowledge, the first steps in analyzing the consequences of communication delays on power system stability in the presence of market-based balancing arrangements were made only recently, in [6]. Therein an upper bound on the market clearing time and price signal delay is computed beyond which a time-discretized version of the single-supplier/single-consumer power-market model proposed in [7] becomes unstable. The results in [6] indicate that the impact of communication delays on the dynamic behavior of the power market can be significant and counterintuitive, and should therefore be anticipated by proper design of balancing arrangements and market regulations.

In this paper we continue in the direction of [6], by investigating the limitations imposed by delays on large-scale ancillary service markets for real-time balancing. In contrast to the modeling employed in [6], we consider multiple (clusters of) generators that are subject to different communication delays originating from a hierarchical tree communication network. The choice for this particular model is motivated by the expectation that future information and communication technology (ICT) will enable every prosumer, i.e., hundreds of millions commercial or domestic parties fulfilling both the role of producer and consumer, to be connected to a near-real-time spot market by exploiting scalable network structures. Examples of these ICT architectures (or multiagent algorithms for distributed optimization) that are being developed today, are the PowerMatcher concept (see e.g., [8], [9]), and the smart-meter platforms developed as part of the InovGrid (see e.g, [10]) and FENIX projects (see e.g, [11]), to name just a few.

A static bid mechanism is taken as starting point, to show that delays can destabilize the power-market feedback loop even in the presence of infinitely fast dynamics. The incentives for participating in ancillary service arrangements should be designed in such a way that rational behavior of prosumers and market agents reinforces the integrity of the future power grid as a whole, even in the presence of delays. Therefore, we attempt to deduce maximum-delay specifications that smart-meter communication platforms should comply with to contribute to robust power balancing and efficient market operation.

By investigating the interaction between price-based control algorithms for real-time balancing and ICT, we aim to provide systematic design rules for unrestricted smart-meter-based ancillary service markets. Efficiently designed ICT-driven market mechanisms could become a valuable tool for efficient realtime balancing and for ensuring stable operation of the future 


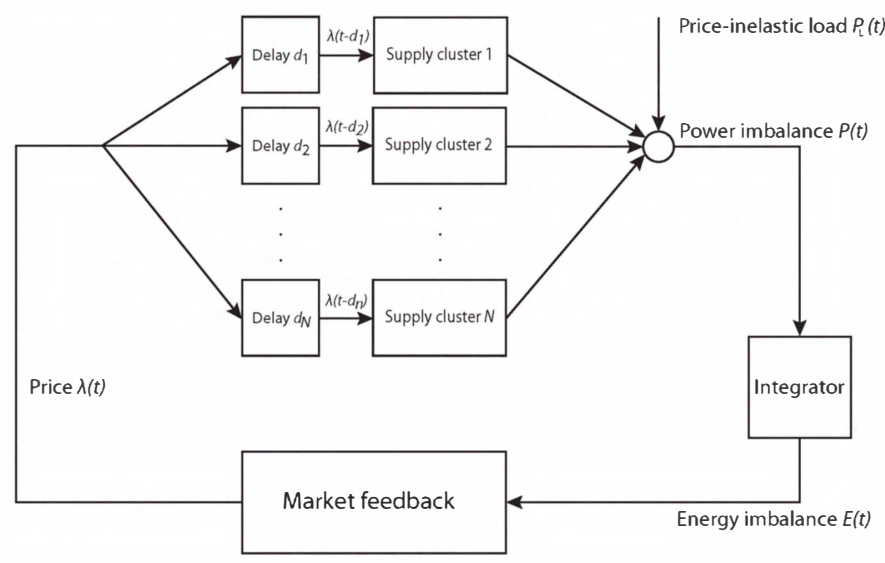

Fig. 1. General market-based power system balancing scheme that is subject to communication delays.

electrical grid as a whole. Moreover, they could alleviate the need for investments in transmission infrastructure, as well as in local sources for ancillary service, such as units for storing electricity.

\section{MODEL AND ASSUMPTIONS}

A schematic overview of a multi-prosumer (producer/consumer) market-based control loop for realtime imbalance management is shown in Fig. 1. The purpose of this feedback scheme is to maintain the balance between supplied and demanded energy by employing a time-varying spot price $\lambda(t)[€ / \mathrm{MW}]$ for electrical power. Most of the near-real-time markets establish this price through frequently updated auctions. In these markets, there is a natural tendency towards further increasing the frequency of price updates, in order to achieve greater economic efficiency and increased robustness with respect to unpredictable fluctuations originating from intermittent and uncontrollable, i.e., priceinelastic, sources such as sun and wind. To analyze some of the issues related to real-time delayed market response in future power systems, we approximate the periodically updated price by a continuous-time signal. The corresponding differential equations for imbalance power, energy and price, based on the model presented in [7], are given below.

Let $\mathcal{M}$ denote the set of generators $\{1,2, \ldots, M\}$ in the network and let $P_{\mathrm{G}, m}(t), P_{\mathrm{L}}(t)$ [MW] be the power produced by generator $m \in \mathcal{M}$ and the total power demand at time $t$ [s], respectively. The energy imbalance $E(t)[\mathrm{MWh}]$ in the network at time $t$ is defined as the time integral of the difference between the total generated and the total demanded power, i.e.,

$$
\dot{E}(t)=\sum_{m \in \mathcal{M}} P_{\mathrm{G}, m}(t)-P_{\mathrm{L}}(t) .
$$

For simplicity and without loosing generality, we assume that all generators are price sensitive, whereas the load is assumed to be completely price inelastic. Price-sensitive loads and price-insensitive generators (such as photovoltaic sources and wind turbines) can still be included in (1), by modeling them as negative generation or negative load, respectively. In interpreting (1), it is important to stress the difference between consumption and demand. With demand we refer to the desired amount of power consumption, which is consumed if the network frequency and voltage equal their nominal values. The actual consumption however, i.e., the usage of power at the actual system frequency and voltage, is always balanced with generation as a result of the law of conservation of energy (if network losses are neglected). So, by considering demand instead of actual consumption, the notion of imbalance becomes well-defined, and balancing becomes a control problem.

The power required for balancing, i.e. $P_{\mathrm{AS}}(t)[\mathrm{MW}]$, is determined by an integral feedback control law on $E$, given by

$$
\dot{P}_{\mathrm{AS}}(t)=-k_{\mathrm{C}} E(t)
$$

where the time constant $\frac{1}{k_{\mathrm{C}}}$, with $k_{\mathrm{C}}>0$, determines the controller's dynamics. Note that in real power systems, it is impossible to measure power and energy imbalance directly. In practice $E$ can be assessed nonetheless, as it is proportionally related to the deviation of network frequency with respect to its nominal value, which is directly measurable at any location in the system.

In the deregulated electrical grid, power production units are owned and controlled by a large number of market players that compete for supply and demand of electrical energy under supervision of a transmission system operator (TSO). The TSO, who is responsible for ensuring reliable operation of the electricity grid, is unable to adapt production according to (2) directly. Instead, it should provide appropriate incentives for maintaining the network balance, in such a way that rational behavior of the market players leads to stable network operation. Many European TSOs have therefore established an intraday market for ancillary service, on which they act as single buyer of balancing power. On this market, requests for $P_{\mathrm{AS}}(t)$ are translated into spot prices for balancing power $\lambda(t)[€ / \mathrm{MW}]$ through a predetermined aggregated bid/supply function $s(\cdot)$, i.e.,

$$
\lambda(t)=s\left(P_{\mathrm{AS}}(t)\right) .
$$

The aggregated market supply curve $s(\cdot)$ is constructed by "horizontally adding" the bid curves of individual market players. Hence, (3) can be rewritten as

$$
P_{\mathrm{AS}}(t)=s^{-1}(\lambda(t))=\sum_{m \in \mathcal{M}} s_{m}^{-1}(\lambda(t))
$$

where the individual inverse bid curves that specify how much power a supplier $m \in \mathcal{M}$ wants to produce against market price $\lambda$, are represented by $s_{m}^{-1}(\lambda)$.

It is assumed that the supply functions are affine, increasing functions of the produced power, i.e., $s_{m}\left(P_{\mathrm{G}, m}\right)=a_{m} P_{\mathrm{G}, m}+$ $b_{m}, m \in \mathcal{M}$, and hence $s\left(P_{\mathrm{AS}}\right)=a P_{\mathrm{AS}}+b$, where $a_{m}, a>0$. Then, the differential equation describing the evolution of the ancillary service spot price is given by

$$
\dot{\lambda}(t)=\frac{\mathrm{d} s\left(P_{\mathrm{AS}}\right)}{\mathrm{d} P_{\mathrm{AS}}} \dot{P}_{\mathrm{AS}}=-a k_{\mathrm{C}} E=:-k_{\mathrm{E}} E,
$$

where the inverse time constant $k_{\mathrm{E}}:=a k_{\mathrm{C}}>0$ determines the dynamics of the price update. It can be shown that feedback law (5) is not sufficient to stabilize the closed-loop system 
depicted in Fig. 1. Therefore, in [12] a modified, damped priceupdate relation is employed, i.e.,

$$
\dot{\lambda}(t)=-k_{\mathrm{E}} E-k_{\lambda} \lambda,
$$

which, for appropriately chosen damping coefficient $k_{\lambda}>0$, results in a stable balancing system.

Rational behavior of price-sensitive suppliers with time constant $\tau_{\mathrm{G}}$ (that cannot exercise market power) is modeled as

$$
\begin{aligned}
\tau_{\mathrm{G}} \dot{P}_{\mathrm{G}, m}(t) & =\lambda(t)-s_{m}\left(P_{\mathrm{G}, m}(t)\right) \\
& =\lambda(t)-a_{m} P_{\mathrm{G}, m}(t)-b_{m}
\end{aligned}
$$

for $m \in \mathcal{M}$. Thus, market parties increase their power output $P_{\mathrm{G}, m}[\mathrm{MW}]$ if $\lambda$ (taken as an exogeneous quantity) exceeds their marginal cost $s_{m}\left(P_{\mathrm{G}, m}\right)$. The corresponding market equilibrium is attained when the market price equals marginal costs.

For more information on the assumptions and limitations of the model presented above, the interested reader is referred to [7], [13].

\section{A. Communication delays}

Many of the smart-meter platforms for real-time pricedriven balancing that are under development today, exploit communication over tree-structured networks such as the one shown in Fig. 2 (see e.g., [8], [9] for more details). These networks provide a scalable and distributed way of coordinating large numbers of dispersed generators and demand response units, whereas their ordered topology facilitates the integration into hierarchical market structures.

Tree-structured communication networks are characterized by a central root node (at the top of the hierarchy) that is connected to the nodes in the last-but-one highest level of the hierarchy. The nodes on this second level of the tree are connected to nodes on the third level, and so forth. Let the levels of the tree be denoted by $n \in \mathcal{N}:=\{1,2, \ldots, N\}$, where the top root is the only node present in the 0 -th level. Each node of the communication network corresponds to either a price-sensitive generator/load or a market aggregator (see [8], [9]), whereas the market-based feedback control law, i.e., the price-forming mechanism described by (6), is implemented in the root node. Assuming that the transmission of a message between two connected nodes in the $n$-th and $(n-1)$-th level takes exactly $T_{\mathrm{c}}$ seconds, the time needed for price signals generated by the root node to reach a level- $n$ node will be $n T_{\mathrm{c}}$ [s]. Hence, the delay-based clustering of generators shown in Fig. 1 directly coincides with the hierarchy defined by the communication network, i.e., all generators at the $n$ th level of the network are lumped in supply cluster $n$ and receive a price signal that is delayed by $d_{n}:=n T_{\mathrm{c}}$ seconds. Introducing the price signal delay in (7) yields supply cluster dynamics

$$
\tau_{\mathrm{G}} \dot{P}_{\mathrm{S}, n}(t)=\lambda\left(t-d_{n}\right)-\sigma_{n}\left(P_{\mathrm{S}, n}\right)
$$

where $P_{\mathrm{S}, n}$ and $\sigma_{n}\left(P_{\mathrm{S}, n}\right):=\alpha_{n} P_{\mathrm{S}, n}(t)-\beta_{n}$ with $\alpha_{n}>0$ represent the total power production and the aggregated supply function of all generators in supply cluster $n \in \mathcal{N}$, respectively.

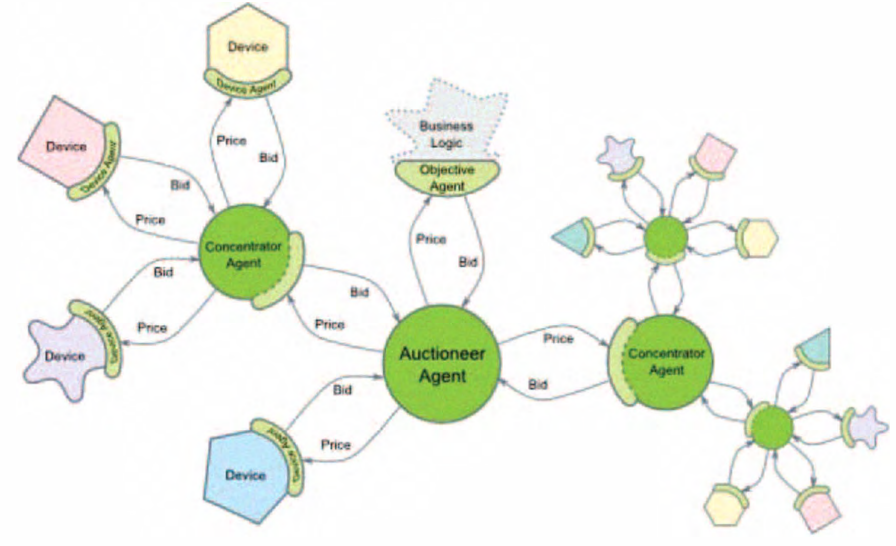

Fig. 2. A hierarchical tree-based communication architecture for exchanging bids or price signals.

\section{STABILITY ANALYSIS}

As algebraic stability analysis of the delayed balancing scheme described in Section II can be tedious, we introduce a number of assumptions to obtain a simplified power-market model for which the closed-loop stability criteria can be assessed analytically.

\section{A. Linear Feedback-Loop Model}

Consider a power system in which the generators respond sufficiently fast to the delayed price signal $\lambda\left(t-d_{n}\right)$ (according to (8)), to be able to approximate their dynamics by the static equilibrium equation

$$
\begin{aligned}
\lambda\left(t-d_{n}\right) & =\sigma_{n}\left(P_{\mathrm{S}, n}(t)\right) \\
& \Rightarrow P_{\mathrm{S}, n}(t)=\sigma_{n}^{-1}\left(\lambda\left(t-d_{n}\right)\right)
\end{aligned}
$$

without changing the model significantly. This is the case if $\tau_{\mathrm{G}} \ll \frac{1}{k_{\lambda}}$, and could be a realistic model of a network in which a large share of electrical energy is produced by fast distributed sources such as (car) batteries and combined heat and power generation (CHP). Moreover, let the supply functions of all clusters be linear, such that the simplified balancing model is given by (1), (6) and (9), where $\sigma_{n}\left(P_{\mathrm{S}, n}\right):=a_{n} P_{\mathrm{S}, n}$ for all $n \in \mathcal{N}$.

We start by analyzing the balancing scheme in the absence of delays, i.e., $d_{n}=0$ for all $n \in \mathcal{N}$. The open-loop frequency response of the corresponding simplified balancing scheme is given by

$$
L(j \omega)=\frac{\frac{\bar{a} k_{\mathrm{E}}}{k_{\lambda}}}{j \omega\left(j \omega \frac{1}{k_{\lambda}}+1\right)}=: \frac{K}{j \omega(j \omega \tau+1)},
$$

where $K:=\frac{\bar{a} k_{\mathrm{E}}}{k_{\lambda}}>0, \bar{a}:=\sum_{n \in \mathcal{N}} \frac{1}{a_{n}}>0, \tau:=\frac{1}{k_{\lambda}}>0$, and negative feedback is assumed. Stability of the closed-loop system with open-loop transfer function $L(j \omega)$ can be assessed using Nyquist's stability theorem, given below (see, e.g., [14] for details).

Theorem III.1 (Nyquist Stability) Consider a closed-loop system with negative open-loop transfer $L(j \omega)$ and $P$ unstable open-loop poles, and let its Nyquist plot, i.e., the polar plot 

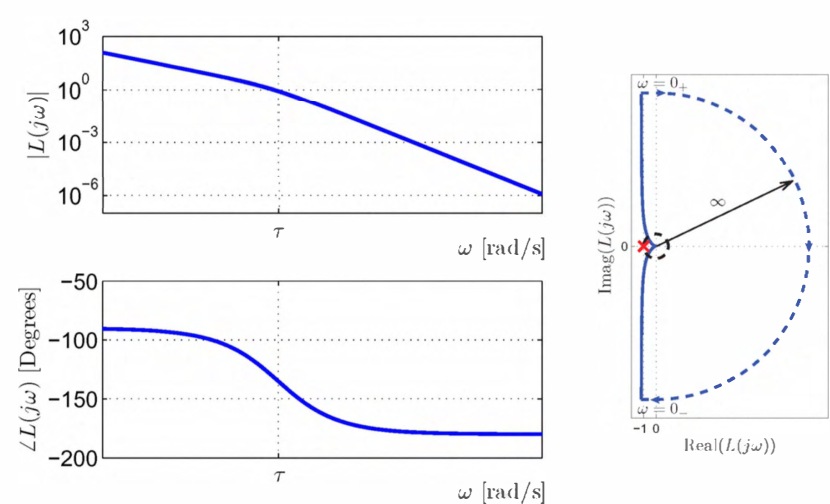

Fig. 3. Gain (top left), phase (bottom left) and Nyquist characteristic (right) of open-loop transfer $L(j \omega)$.

of $|L(j \omega)|$ and $\angle L(j \omega)$, be given. This system is stable if a representative point $s$, moving along the Nyquist plot in clockwise direction, encircles the point $-1+j 0 P$ times in the counterclockwise direction.

Since transfer function (10) has no unstable poles, i.e., poles with real parts that are larger than 0 , by Theorem III. 1 the balancing system with frequency response $\frac{L(j \omega)}{1+L(j \omega)}$ is stable if its Nyquist plot does not encircle the point $-1+j 0$ (in counterclockwise direction). In order to draw the Nyquist plot of (10), we require expressions for the open-loop gain $|L(j \omega)|$ and phase $\angle L(j \omega)$, given below.

$$
\begin{aligned}
& |L(j \omega)|=\frac{K}{\omega \sqrt{\tau^{2} \omega^{2}+1}} \\
& \angle L(j \omega)=-180+\arctan \left(\frac{1}{-\omega \tau}\right) .
\end{aligned}
$$

Fig. 3 shows the open-loop gain, phase and Nyquist plots of (10). Note that the infinite-radius semicircle in the Nyquist plot is a direct consequence of $L(j \omega)$ having a pole on the imaginary axis, corresponding to the integrating action in (1). The Nyquist plot does not encircle $-1+j 0$, regardless of $K, \tau>0$, which implies stability of the simplified balancing scheme in the absence of delays.

Next, we address the stability of the simplified balancing scheme when all price signals are delayed by $T_{\mathrm{c}}[\mathrm{s}]$. This is the case if the balancing scheme consists of one supply cluster only, or if the market outcome requires a single cluster to supply the total amount of requested balancing power. According to Theorem III.1, this system is stable if the Nyquist plot of $L(j \omega) e^{-j \omega T_{\mathrm{c}}}$ does not encircle the -1 point. Since the delay term $e^{-j \omega T_{\mathrm{c}}}$ has unity gain and phase $\angle e^{-j \omega T_{\mathrm{c}}}=-\omega T_{\mathrm{c}}$, the Nyquist plot of $L(j \omega) e^{-j \omega T_{\mathrm{c}}}$ follows by rotating all points on the Nyquist curve in Fig. 3 clockwise around the origin by $\omega T_{\mathrm{c}}$ [rad]. Consequently, the delayed closed-loop system is unstable if the delay $T_{\mathrm{c}}$ is large enough to rotate the cross-over point of $L(j \omega)$ (i.e. the point corresponding to frequency $\omega_{0}$ such that $\left|L\left(j \omega_{0}\right)\right|=1$ ) along the unit circle over the point $-1+j 0$. The cross-over frequency $\omega_{0}$ of $L(j \omega)$ is given by

$$
\omega_{0}=\sqrt{\frac{1}{2 \tau^{2}}\left(-1+\sqrt{1+4 K^{2} \tau^{2}}\right)}
$$

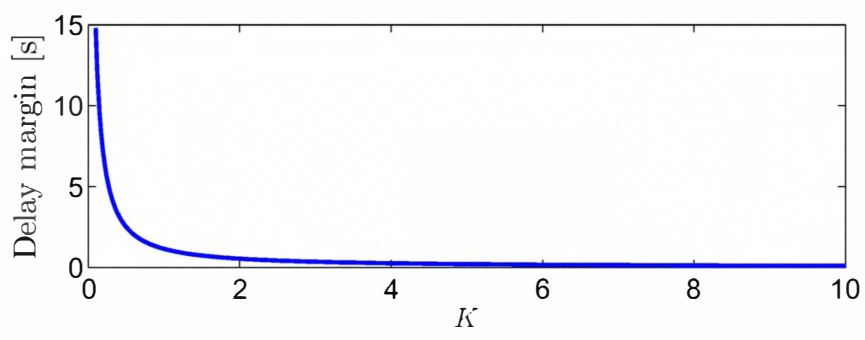

Fig. 4. Delay margin as function of feedback gain $K:=\frac{\bar{a} k_{\mathrm{E}}}{k_{\lambda}}$ for $\tau=1$.

and the corresponding open-loop phase is given by

$$
\angle L\left(j \omega_{0}\right)=-180+\arctan \left(\frac{\sqrt{2}}{\sqrt{-1+\sqrt{1+4 K^{2} \tau^{2}}}}\right) .
$$

Hence, the simplified balancing scheme has a phase margin $\phi_{\mathrm{PM}}:=\angle L\left(j \omega_{0}\right)-(-180)$, i.e., the amount by which the phase of $L(j \omega)$ exceeds $-180^{\circ}$, of

$$
\phi_{\mathrm{PM}}=\arctan \left(\frac{\sqrt{2}}{\sqrt{-1+\sqrt{1+4 K^{2} \tau^{2}}}}\right) .
$$

Thus, the closed-loop delayed balancing scheme is unstable if the delay $T_{\mathrm{c}}$ exceeds the delay margin $\frac{\phi_{\mathrm{PM}}}{\omega_{0}}[\mathrm{~s}]$, which is plotted in Fig. 4 as a function of $K$ for $\tau=1$. Fig. 4 shows that the delay margin converges asymptotically to 0 as feedback gain $K$ is increased to infinity.

\section{B. Multi-Delay Linear Feedback-Loop Model}

Consider the simplified balancing scheme described by (1), (6) and (9), where $\sigma_{n}\left(P_{\mathrm{S}, n}\right):=a_{n} P_{\mathrm{S}, n}$, in closed-loop with the hierarchical-tree based delay network described in Section II-A. A schematic representation of the corresponding closed-loop model is shown in Fig. 5, where $H(j \omega)$ denotes the open-loop transfer of the integrator and market dynamics and where the transfer function of the delayed generator network is referred to as $D(j \omega):=\sum_{n \in \mathcal{N}} \frac{1}{a_{n}} e^{-j \omega T_{\mathrm{c}}}$. By Theorem III.1, this closed-loop balancing scheme is stable if the Nyquist plot of $H(j \omega) D(j \omega)$ does not encircle the point -1 . In contrast to the approach described in the previous subsection, because $|D(j \omega)| \neq 1$ for all $\omega \in \mathbb{R}$ it is not possible to derive an upper bound on the maximum delay $N T_{\mathrm{c}}$, and therefore also on the maximum depth of the communication tree, by evaluating the phase margin of $H(j \omega)$. Hence, algebraic stability analysis of the tree-based communication network balancing scheme can be tedious in general, although relatively simple expressions for the upper bounds on $N$ or $T_{\mathrm{c}}$ can be found for specific cases of bid curves or delay structures. In this section, we focus on a network in which the aggregated bid curves of all supply clusters are equal and fixed, such that $P_{\mathrm{S}, n}(t):=P_{\mathrm{S}}(t)=\bar{\alpha} \lambda\left(t-d_{n}\right)$ for all $n \in \mathcal{N}$. By exploiting the linearity of the bid curves, the open-loop transfer function of the multi-delay scheme can be written as $G(j \omega):=D_{\alpha}(j \omega) H_{\alpha}(j \omega)$, with

$$
H_{\alpha}(j \omega)=\frac{\frac{k_{\mathrm{E}}}{\bar{\alpha} k_{\lambda}}}{j \omega\left(j \omega \frac{1}{k_{\lambda}}+1\right)}=: \frac{K_{\alpha}}{j \omega(j \omega \tau+1)},
$$




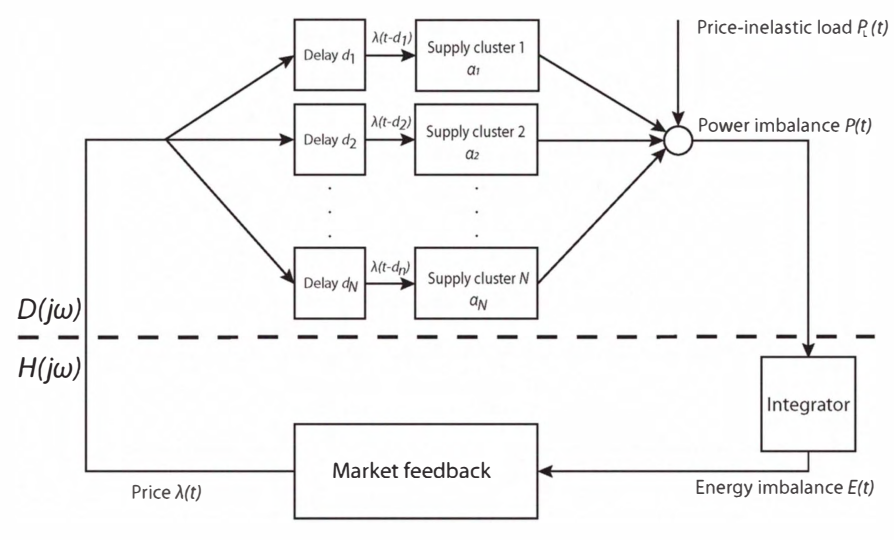

Fig. 5. Stability-analysis based partitioning of the multi-delay market-driven balancing scheme.

where $K_{\alpha}:=\frac{k_{\mathrm{E}}}{\bar{\alpha} k_{\lambda}}, \tau:=\frac{1}{k_{\lambda}}$, and with

$$
\begin{aligned}
D_{\alpha}(j \omega) & =\sum_{n=1}^{N} e^{-j \omega n T_{\mathfrak{c}}} \\
& =e^{-j \frac{N+1}{2} \omega T_{\mathfrak{c}}}\left\{e^{j \frac{N-1}{2} \omega T_{\mathfrak{c}}}+e^{j \frac{N-3}{2} \omega T_{\mathfrak{c}}}+\ldots\right. \\
& \left.\quad+e^{-j \frac{N-3}{2} \omega T_{\mathfrak{c}}}+e^{-j \frac{N-1}{2} \omega T_{\mathfrak{c}}}\right\},
\end{aligned}
$$

such that for even $N$, i.e., $N:=2 k$ for some positive integer $k=1,2, \ldots$, this yields

$$
D_{\alpha}(j \omega)=2 e^{-j \frac{2 k+1}{2} \omega T_{\mathrm{c}}} \sum_{i=1}^{k} \cos \left(\left(k-i+\frac{1}{2}\right) \omega T_{\mathrm{c}}\right)
$$

and such that for odd $N$, i.e., $N:=2 k-1$ for some positive integer $k=1,2, \ldots$, this gives

$$
D_{\alpha}(j \omega)=2 e^{-j k \omega T_{\mathrm{c}}}\left\{\sum_{i=1}^{k-1} \cos \left((k-i) \omega T_{\mathrm{c}}\right)+\frac{1}{2}\right\} .
$$

Hence, the gain and phase of $D_{\alpha}(j \omega)$ are expressed as

$$
\begin{aligned}
\left|D_{\alpha}(j \omega)\right|^{2} & = \begin{cases}\left(2 \sum_{i=1}^{k} \cos \left(\left(k-i+\frac{1}{2}\right) \omega T_{\mathrm{c}}\right)\right)^{2} & (N \text { even }) \\
\left(2\left\{\sum_{i=1}^{k-1} \cos \left((k-i) \omega T_{\mathrm{c}}\right)+\frac{1}{2}\right\}\right)^{2} & (N \text { odd })\end{cases} \\
\angle D_{\alpha}(j \omega) & =-\frac{N+1}{2} \omega T_{\mathrm{c}} .
\end{aligned}
$$

Now, a lower bound on the maximum $T_{\mathrm{c}}$ for which the multi-delay scheme is stable can be derived, by bounding the frequency-dependent gain $\left|D_{\alpha}(j \omega)\right|$ from above by the constant $N$. Because the open-loop transfer of this "worst-case scheme" is given by $N H_{\alpha}(j \omega) e^{-\frac{N+1}{2} \omega T_{\mathrm{c}}}$, with $\left|e^{-\frac{N+1}{2} \omega T_{\mathrm{c}}}\right|=$ 1 , we know that the system remains stable for at least delays up to $T_{\mathrm{c}}$ such that the Nyquist plot of $N H_{\alpha}(j \omega)$ is rotated over the point -1 . By observing that the transfer function $N H_{\alpha}(j \omega)$ is a scaled version of the open-loop transfer $L(j \omega)$ considered in Subsection III-A, the cross-over frequency and phase and delay margins of $N H_{\alpha}(j \omega)$ are found straightforwardly. The cross-over frequency $\omega_{0}$ of $N H_{\alpha}(j \omega)$ is given by

$$
\omega_{0}=\sqrt{\frac{1}{2 \tau^{2}}\left(-1+\sqrt{1+4 N^{2} K_{\alpha}^{2} \tau^{2}}\right)}
$$

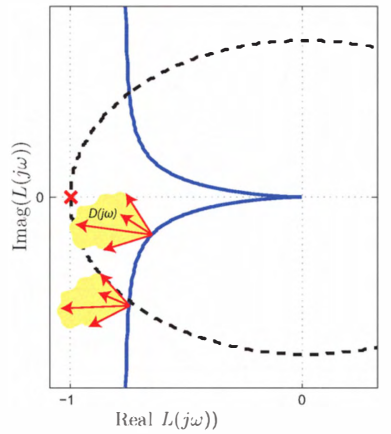

Fig. 6. Numerical method of finding the maximum non-destabilizing communication delay, in case of nonlinear supply functions.

and the corresponding open-loop phase is given by

$$
\angle N H_{\alpha}\left(j \omega_{0}\right)=-180+\arctan \left(\frac{\sqrt{2}}{\sqrt{-1+\sqrt{1+4 N^{2} K_{\alpha}^{2} \tau^{2}}}}\right) \text {. }
$$

Hence, in case all supply cluster have equal linear bid curves, the phase margin $\phi_{\mathrm{PM}}:=\angle N H\left(j \omega_{0}\right)-(-180)$ of the tree-based communication-network power-market balancing scheme can be lower bounded as

$$
\bar{\phi}_{\mathrm{PM}}>\arctan \left(\frac{\sqrt{2}}{\sqrt{-1+\sqrt{1+4 N^{2} K_{\alpha}^{2} \tau^{2}}}}\right) .
$$

Thus, the closed-loop delayed balancing scheme is stable for delays $T_{\mathrm{c}}$ up to at least $\frac{\bar{\phi}_{\mathrm{PM}}}{\omega_{0}}[\mathrm{~s}]$, which converges asymptotically to 0 as feedback gain $\stackrel{\omega}{K}$ or communication network depth $N$ is increased to infinity.

Remark III.2 A numerical procedure to determine the maximum allowed $T_{\mathrm{c}}$ such that the multi-delay balancing scheme is stable, should look for the smallest delay (given a fixed $N$ ) or number of supply clusters (given a fixed $T_{\mathrm{c}}$ ) for which the Nyquist plot of $H(j \omega) D(j \omega)$ encircles the point -1 . Moreover, in practice the aggregated bid curves of individual supply clusters will be nonlinearly rather than linearly depending on price, such that the contribution of each cluster to the production of $P_{\mathrm{AS}}$ will vary with $\lambda$. In this case, numerical analysis should focus on finding the worst-case possible combination of $\sigma_{n}^{-1}(\lambda), n \in \mathcal{N}$, over the range of allowable prices $0<\lambda<\lambda_{\max }[€]$, such that the Nyquist plot of $H(j \omega) D(j \omega)$ is shifted over the point -1 . Fig. 6 shows that this search can for instance be implemented by shifting all points on the plot of $H(j \omega)$ by the vectors in the yellow set spanned by $\left\{\sigma_{n}(\lambda) e^{-j n \omega T_{\mathrm{c}}} \mid n \in \mathcal{N}, 0<\lambda<\lambda_{\max }, T_{\mathrm{c}}>0\right\}$.

Remark III.3 In the current market arrangements for ancillary service, the selection of generators for the production of balancing power completely depends on price and market objectives, irrespective of physical restrictions such as reaction speed or response delays. It should be clear from the analysis in this section that dynamics and delays can have significant effects on the performance and stability of the control loop for power balancing, and should therefore be anticipated by 
balancing arrangements and market regulations that take both economic and control-oriented objectives into account.

\section{CONCLUSIONS}

Real-time balancing of the European electricity grid will become increasingly dependent on market-based control mechanisms that are enabled by connecting millions of prosumers to an open communication network. The use of communication systems inevitably introduces delays in the energy balancing control loop, which could endanger market operation and stability of the electricity grid. By investigating the interaction between price-based control algorithms for real-time balancing and information and communication technology, we proposed a number of systematic design rules for ensuring safe and stable operation of ancillary service markets in closed-loop with communication delays.

\section{ACKNOWLEDGEMENTS}

This research is part of the EOS-Regelduurzaam (Sustainable energy research) project that is funded by SenterNovem, an agency of the Dutch Ministry of Economic Affairs.

\section{REFERENCES}

[1] P. P. J. van den Bosch, A. Jokić, J. Frunt, W. L. Kling, F. Nobel, P. Boonekamp, W. de Boer, and R. M. Hermans, "Incentives-based ancillary services for power system integrity," in International Conference on the European Energy Market, vol. 6, Leuven, Belgium, May 2009, pp. 1198-1/7.

[2] S. Stoft, Power System Economics: Designing Markets for Electricity. Kluwer Academic Publishers, 2002.

[3] S. Bhowmik, K. Tomsovic, and A. Bose, "Communication models for third party load frequency control," IEEE Transactions on Power Systems, vol. 19, no. 1, pp. 543-548, February 2004.
[4] X. Yu and K. Tomsovic, "Application of linear matrix inequalities for load frequency control with communication delays," IEEE Transactions on Power Systems, vol. 19, no. 3, pp. 1508-1515, August 2004.

[5] L. Jiang, W. Yao, J. Y. Wen, S. J. Cheng, and Q. H. Wu, "Delaydependent stability for load frequency control with constant and timevarying delays," in IEEE Power Energy Society General Meeting, July 2009, pp. 1-6.

[6] J. Nutaro and V. Protopopescu, "The impact of market clearing time and price signal delay on the stability of electric power markets," IEEE Transactions on Power Systems, vol. 24, no. 3, pp. 1337-1345, August 2009.

[7] F. L. Alvarado, "The dynamics of power system markets," Department of Electrical and Computer Engineering, University of Wisconsin, Madison, WI, USA, Tech. Rep. PSerc-97-01, March 1997.

[8] K. Kok, M. Scheepers, and R. Kamphuis, Intelligent Infrastructures, ser. Intelligent Systems, Control and Automation: Science and Engineering. Springer, 2010, vol. 42, ch. Intelligence in electricity networks for embedding renewables and distributed generation, pp. 179-210.

[9] K. Kok, C. Warmer, and R. Kamphuis, "Powermatcher: Multiagent control in the electricity infrastructure," in International Joint Conference on Autonomous Agents and Multiagent Systems, vol. 4, Utrecht, The Netherlands, 2005, pp. 75-82.

[10] N. Melo, R. Prata, R. Gonçalves, and F. Mira, "Microgeneration in Portugal - EDP experience and future perspectives," in International Conference on Electricity Distribution (CIRED), vol. 20, Prague, Czech Republic, June 2009.

[11] I. Bel, A. Valenti, J. M. Corera, and P. Lang, "Innovative operation with aggregated distributed generation," in International Conference on Electricity Distribution (CIRED), vol. 19, Vienna, Austria, May 2007.

[12] F. L. Alvarado, J. Meng, C. L. DeMarco, and W. S. Mota, "Stability analysis of interconnected power systems coupled with market dynamics," IEEE Transactions on Power Systems, vol. 16, no. 4, pp. 695-701, November 2001.

[13] A. Jokić, E. H. M. Wittebol, and P. P. J. van den Bosch, "Dynamic market behavior of autonomous network-based power systems," European Transactions on Electrical Power, vol. 16, no. 5, pp. 533-544, September 2006.

[14] G. F. Franklin, D. J. Powell, and A. Emami-Naeini, Feedback Control of Dynamic Systems. London, UK: Prentice Hall, 2006. 